\title{
Expression of the zic1, zic2, zic3, and zic4 genes in early chick embryos
}

\author{
Ariel R McMahon and Christa S Merzdorf*
}

\begin{abstract}
Background: The zic genes encode a family of transcription factors with important roles during early development. Since little is known about zic gene expression in chick embryos, we have characterized the expression patterns of the zic1, zic2, zic3, and zic4 (zic 1-4) genes during neurulation and somitogenesis.

Findings: We used in situ hybridization to analyze the expression patterns of the zic1-4 genes during early chick development (HH stages 7-19). The zic1-3 genes showed both overlapping and gene-specific expression patterns along the length of the dorsal neural tube and in the dorsal parts of the somites. In addition, unique expression domains of zic genes included: zic 2 in the neural plate, periotic mesoderm and limb buds; zic 3 in the paraxial mesoderm surrounding the neural plate, in presomitic mesoderm and in the most recently formed epithelial somites; zic2 and zic3 in developing eyes. zic4 expression was limited to dorsal fore- and midbrain regions and, unlike the expression of the zic $1-3$ genes, zic4 expression was not detected in the hindbrain and trunk. This was in contrast to more extensive zic4 expression in other vertebrates.

Conclusions: The zic1-3 genes were expressed in both overlapping and unique domains within the neural tube, somites and other ectoderm and mesoderm-derived structures in the future head and trunk. zic4 expression, however, was limited to dorso-anterior regions of the future brain. This is the first comprehensive study of zic1-4 gene expression in chick embryos during neurulation and somitogenesis.
\end{abstract}

\section{Background}

The $z i c$ genes encode a family of zinc finger transcription factors. Five $z i c$ genes are typically found in vertebrates (zic1-5), where they guide a variety of developmental processes [1] and zic genes play significant roles during early neural patterning and neural crest formation [2-11]. Although zic genes may be able to partially compensate for each other [12,13], mutations in individual Zic genes in mice and humans produce distinct phenotypes [14]. For example, compromised expression of the Zic2 gene results in neural tube defects and mutation of the Zic3 gene causes left-right abnormalities in addition to less severe neural tube defects [15-23]. In addition, mutations in the Zic1 or Zic4 genes result predominantly in cerebellar abnormalities [13,24]. Collectively, these phenotypes illustrate the relevance of $z i c$ genes to early developmental processes. However, much further study is required to

* Correspondence: merzdorf@montana.edu

1 Department of Cell Biology and Neuroscience, Montana State University, Bozeman, MT 59717, USA

Full list of author information is available at the end of the article elucidate the mechanisms that underlie the phenotypes associated with mutations of individual $z i c$ genes.

Chick embryos represent a major developmental model system that remains largely untapped for the study of $z i c$ genes. This is partly due to a lack of characterization of $z i c$ gene expression during chick development, which has been mainly restricted to studies of the $z i c 1$ gene [25-28]. Specifically, there are no published micrographs of zic2 gene expression patterns prior to stage 23 [27] and descriptions of zic3 expression are limited to brain and anterior trunk regions at stages 10,12 , and 17 [29], and to a stage 26 embryo [28]. In addition, the expression of zic4 in chick embryos has not been described. In this study, we thoroughly examine zic1-4 gene expression in stage 719 chick embryos during neurulation and somitogenesis. Care was taken to use gene-specific probes in order to avoid potential cross reactivity among zic genes. This study differs from previous work by examining zic1-3 expression at earlier stages of chick development (beginning with Hamburger Hamilton $\mathrm{HH}$ stage $6+/ 7$ ), in reporting for the first time on the expression of the zic4 
gene, and by providing a comprehensive comparison of zic1-4 expression patterns up to stage $18 / 19$. Thus, this is the most thorough comparative expression study of the zic1-4 genes during early development in chick embryos. As such, it contributes a foundation for future studies of Zic transcription factors during early neural and somite development, where $z i c$ genes are known to play important roles.

\section{Results and Discussion}

\section{Genomic location of the zic1-4 genes}

The genomes of most vertebrates contain five zic genes (reviewed in Merzdorf, 2007). In the chicken genome, the $z i c 1$ and zic4 genes are adjacent and transcribed in opposite directions on chromosome 9, while the zic2 and zic3 genes are located on chromosomes 1 and 4, respectively. In other vertebrates, the $z i c 1$ and zic4 genes and the $z i c 2$ and $z i c 5$ genes are adjacent and transcribed in opposite directions. However, zic5 has not yet been identified in the chicken genome. In mouse, the Zic5 gene is located between the Zic2 and $C l y b l$ genes. The equivalent intergenic region in the chicken genome sequence contains several gaps and will thus require additional work to conclusively demonstrate the presence or absence of a zic5 gene.

Members of the zic family show high sequence similarity, particularly throughout their zinc finger domains and in the regions immediately flanking them. Therefore, we used the published cDNA sequence for chicken zic1 [25] and the sequence of the chicken genome to select regions for the zic1-4 genes that were highly specific for each gene. Antisense RNAs for in situ hybridization were synthesized from these regions and used to study zic1-4 gene expression in whole embryos and cryosections.

\section{Comparison of zic1-4 gene expression patterns}

We describe zic1-4 gene expression during neurulation and somite formation in chick embryos spanning stage $\mathrm{HH} 6 / 7$ to stage $\mathrm{HH} 18 / 19$. Head neural fold formation begins at stage $6 / 7$, somite formation at stage 7 , and neural tube closure starts at the level of the mesencephalon at stage 8 (4-6 somites). During stages 6-15, gastrulation, neural plate formation, somite formation, and neural tube closure progress in an anterior to posterior direction. In stage 18/19 embryos, the posterior neuropore has closed, the tailbud has formed and limb buds have begun to develop [30,31]. The expression levels of the zic1-3 genes were extremely low and detectable only slightly above background in early embryos at stages $6 / 7$ and up to stage 12. The zic4 gene was not expressed in these early embryos. In stage 14/15 and 18/19 embryos, the expression of the zic1-3 genes in the head was substantially stronger and the zic4 gene was expressed in head regions.

\section{Brain}

In the developing brain, the expression patterns of zic1-3 overlapped extensively, but differed significantly from that of zic4. The expression levels of the zic1-3 genes were very low in embryos at early stages and became more robust in stage 14 and older embryos. At stage 7, zic1 was expressed in the anterior head fold (Figure 1A). In contrast, zic2 was expressed in the head fold and along the entire anterior-posterior axis of the neural plate, including the midbrain region (Figure $2 \mathrm{~A}, \mathrm{~B}$ ). At stage $7, z i c 3$ was expressed in discontinuous regions in the neural folds of the future forebrain and hindbrain (Figure 3A). At stage 8 , the $z i c 1$ and $z i c 3$ genes were expressed in the future forebrain and hindbrain (Figures 1B; 3B). By stage 9, the forebrain expression domains of zic1-3 were very similar and well defined (Figures 1C, 2C, 3C). In the midbrain, zic2 expression ceased transiently (Figure 2C), resulting in a period during which no zic genes were expressed in the midbrain region. In the hindbrain, zic1 expression was limited to rhombomere r4 (Figure 1C, E; white arrowheads), while $z i c 2$ and $z i c 3$ were expressed in almost identical patterns in most of the hindbrain at stage 9 (Figures 2C, 3C) and throughout the brain at stage 11 (Figures 2E, F; 3F). By stage 14/15, the expression patterns of zic1-3 were highly similar and continuous along the forebrain, midbrain, and hindbrain (Figure 4A-C, EG). Although expression of zic1-3 in the brain increased in stage $18 / 19$ embryos, the general expression patterns remained largely unchanged from those at stage 14/15 (Figure 5A-C, I-K). While the expression patterns of zic13 overlapped extensively, they differed significantly from that of zic4. Expression of zic4 could only be detected from stage 14, when it was restricted to the anterior telencephalon (arrow, Figure 4D). By stage 18/19, its expression extended to the diencephalon (in a region posterior to that of zic1-3 expression) and to the mesencephalon (Figure 5D, H, L), but not to the hindbrain.

The observed expression of the zic1-3 genes in the chick forebrain can be related to deficiencies in neural development observed in mice and humans with compromised Zic gene expression. Among the zic genes in the chick, $z i c 2$ showed the earliest and most extensive expression in the anterior neural plate/head fold (Figure 2A) and, accordingly, compromised Zic2 expression in mice or humans causes holoprosencephaly, in which part of the forebrain does not develop properly [16,20,23,32]. Further, mutations in the Zic1 or Zic3 genes alone do not cause obvious forebrain abnormalities but Zic1/Zic3 compound mutant mice show forebrain defects that are very similar, although not as severe, as those observed in Zic2 hypomorphs [11]. This indicates that Zic1, 2, and 3 are involved in forebrain development of mouse embryos. The expression patterns of the zic1-3 genes in chick 


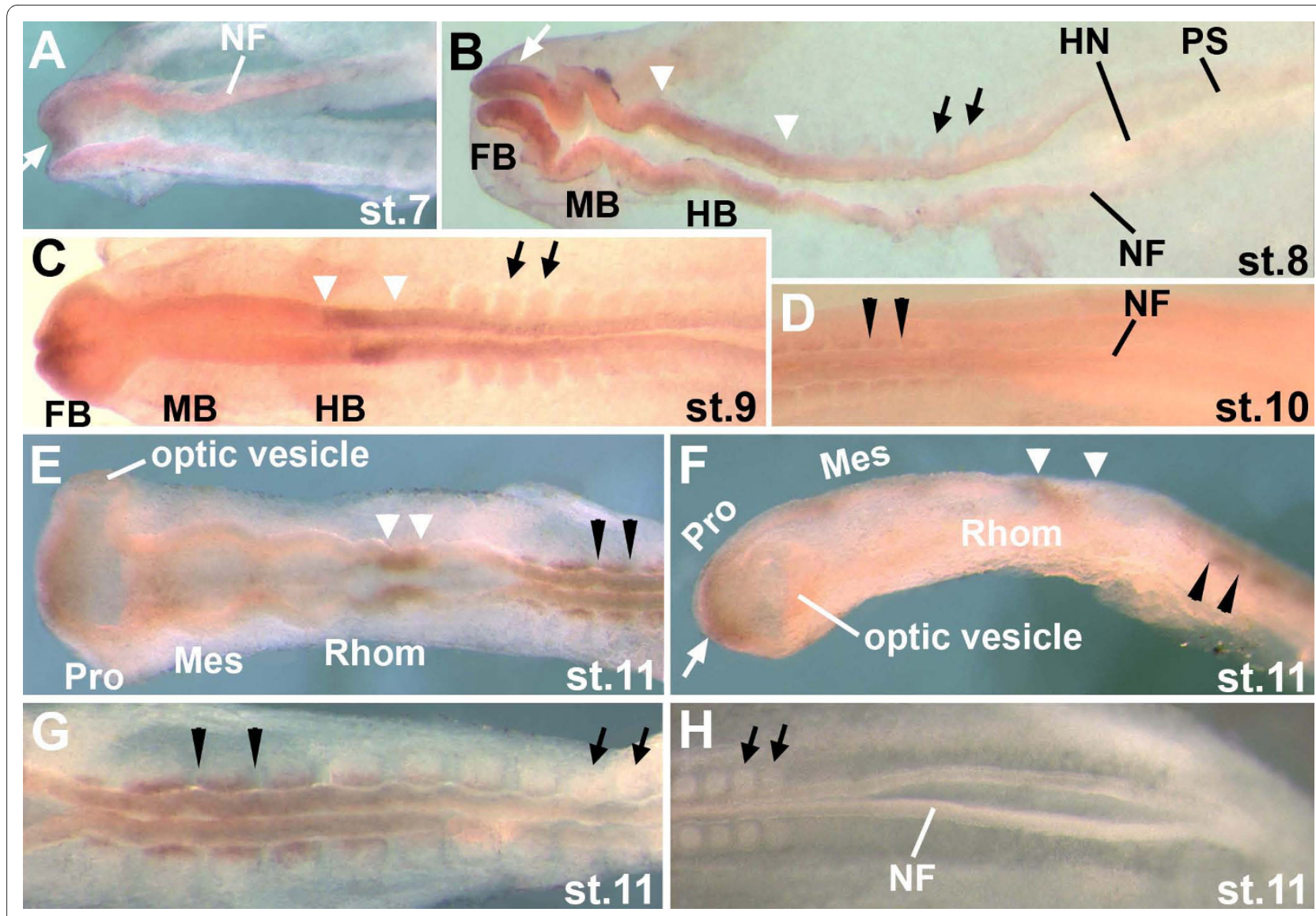

Figure 1 Expression of the zic1 gene in whole mount chick embryos at $\mathrm{HH}$ stages 7-11 determined by in situ hybridization. A: In stage 7 embryos, zic 1 is expressed at very low levels in the most anterior portion of the head fold (white arrow). B: zic 1 is expressed in the neural folds of the future forebrain (white arrow) and hindbrain (white arrowheads) at stage 8. It is not expressed in the future spinal cord or in somites (black arrows). C: By stage 9 , zic 1 is expressed in the anterior region of the future forebrain and in a domain of the future hindbrain (white arrowheads). D: Very weak zic1 expression in anterior somites is first observed at stage 10 (black arrowheads). E (dorsal view), F (side view): zicl expression in anterior somites becomes more robust by stage 11 (black arrowheads), as does zicl expression in the anterior portion of the trunk neural tube (E). In the brain, zicl continues to be expressed in the anterior prosencephalon (best seen in F, white arrow) and in the limited hindbrain domain (best seen in E, white arrowheads). zic1 is not expressed in the optic vesicles. G: At stage 11, anterior somites express zicl, while it is not expressed in posterior somites. zicl expression in the trunk neural tube diminishes towards posterior regions. $\mathrm{H}$ : zicl is not expressed in the neural tube, neural folds, or somites of the posterior trunk in stage 11 (and older) embryos. Overall, expression levels of zicl are very low in these early stage embryos. FB: future forebrain; MB: future midbrain; HB: future hindbrain; HN: Hensen's Node; PS: primitive streak; NF: neural folds; Pro: prosencephalon; Mes: mesencephalon; Rhom: rhombencephalon; white arrowheads: hindbrain expression domain of zic1; white arrow: forebrain expression domain of zic1; black arrows: somites not expressing zic1; black arrowheads flank somites expressing zic1; the anterior of the embryos in all figures is to the left.

embryos suggest that these genes are involved in forebrain development as well.

The importance of Zic transcription factors in brain development is also suggested by experiments in zebrafish and Xenopus. In zebrafish, the zic2 gene is required during formation of the anterior diencephalon [33] and the zic2 and zic5 genes are important during dorsal midbrain development [10]. Further, the zic1 and zic4 genes are necessary for hindbrain ventricle morphogenesis from the level of $\mathrm{r} 2$ towards the posterior [3]. These results corroborate the importance of $z i c 1$ and $z i c 2$ during brain development. Xenopus laevis embryos express zic1-5 during early development [34]. Several genes that are regulated by zic genes in Xenopus embryos are expressed in domains throughout the brain. For example, Zic1 induces expression of the wnt1 and en-2 genes and, therefore, is likely to play a role in midbrain/ hindbrain boundary (MHB) development [4,5]. Since chicken zic1 does not appear to be expressed in the region of the early MHB (Figure 1B), zic2 or zic3 (Figures $2 \mathrm{~B}, 3 \mathrm{~B}$ ) may potentially play roles in $\mathrm{MHB}$ formation in birds. Other genes that are induced by zic genes in Xenopus include the forebrain/midbrain boundary gene wnt $8 b$ [5], the dorsal neural tube gene pax3, the hindbrain genes krox20 [4] and Xfeb, which regulates hoxB1 expression [35]. hoxB1 is expressed specifically in $\mathrm{r} 4$ [36], where 


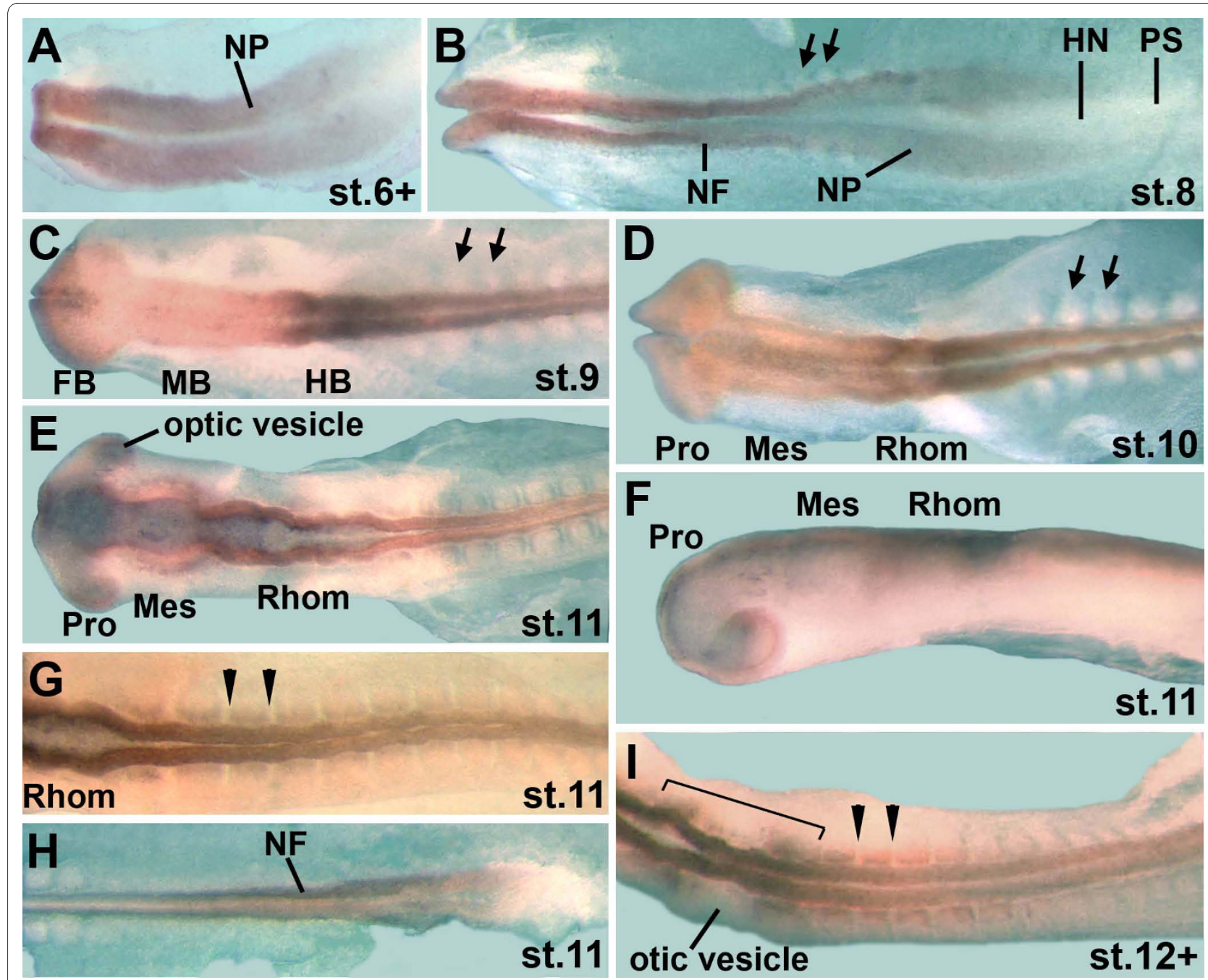

Figure 2 Expression of the zic2 gene in chick embryos at HH stages 6+ to 12 . A: zic2 is expressed in all of the head fold and neural plate region of stage $6+$ embryos. B: At stage 8, zic2 expression continues in the neural folds and throughout the neural plate along the entire anterior-posterior axis of the embryo. C: zic2 expression is downregulated in much of the forebrain and midbrain regions of stage 9 embryos. zic2 expression persists in a small domain of the forebrain and in a large region of the hindbrain. Contiguous with its expression in the hindbrain, zic 2 is expressed in the trunk neural tube. D: zic2 is not yet expressed in somites of stage 10 embryos. E, F: dorsal view (E) and side view (F) of stage 11 embryo; although zic2 expression appears weaker in the mesencephalon region (E), the side view shows that zic2 expression is present along the entire dorsal brain and trunk neural tube (F). The optic vesicles express zic2 at stage 11. G: Weak zic2 expression begins in the anterior somites of stage $11 \mathrm{embryos}$. H: zic2 is expressed in the most posterior neural tube and neural folds. I: in stage 12+ embryos, zic2 expression in anterior somites is more robust and zic 2 is expressed in the periotic mesoderm (bracket). Overall, expression levels of zic 2 are very low in early stage embryos. Abbreviations as in legend for Figure 1; NP: neural plate; black arrows: somites not expressing zic2; black arrowheads flank somites expressing zic2; bracket: periotic mesoderm.

early chick zic1 was expressed (Figure 1C, E). Further, direct targets of Zic1 in Xenopus include genes that modulate retinoic acid signaling, suggesting further roles for zic genes in hindbrain development [37]. Thus, the expression patterns in the future brain of early chick embryos supports numerous roles for zic genes in neural development.

Eyes

The developing eyes in stage 9 to stage 18/19 chick embryos did not express $z i c 1$ or $z i c 4$ (Figures $1,4,5$ ). zic2 expression began in the optic vesicles at stage 11 (Figure
2E, F) and $z i c 3$ expression at stage 13 (Figure $3 \mathrm{H}$ ). All four zic genes were expressed in the optic stalk (Figure 5E-H). The significance of $z i c 2$ and $z i c 3$ expression for optic vesicle development remains to be determined.

\section{Neural tube of the trunk}

In chick, the zic1-3 genes were expressed in the neural tube of the trunk. zic3 expression preceded zic1 expression in the anterior trunk neural tube (stage $7 / 8$ for $z i c 3$; stage 9 for zic1) and, while expression levels were low, the expression of both genes tapered towards the caudal region (Figures $1 \mathrm{C} ; 3 \mathrm{~B}, \mathrm{C}$ ). zic2 expression in the trunk 


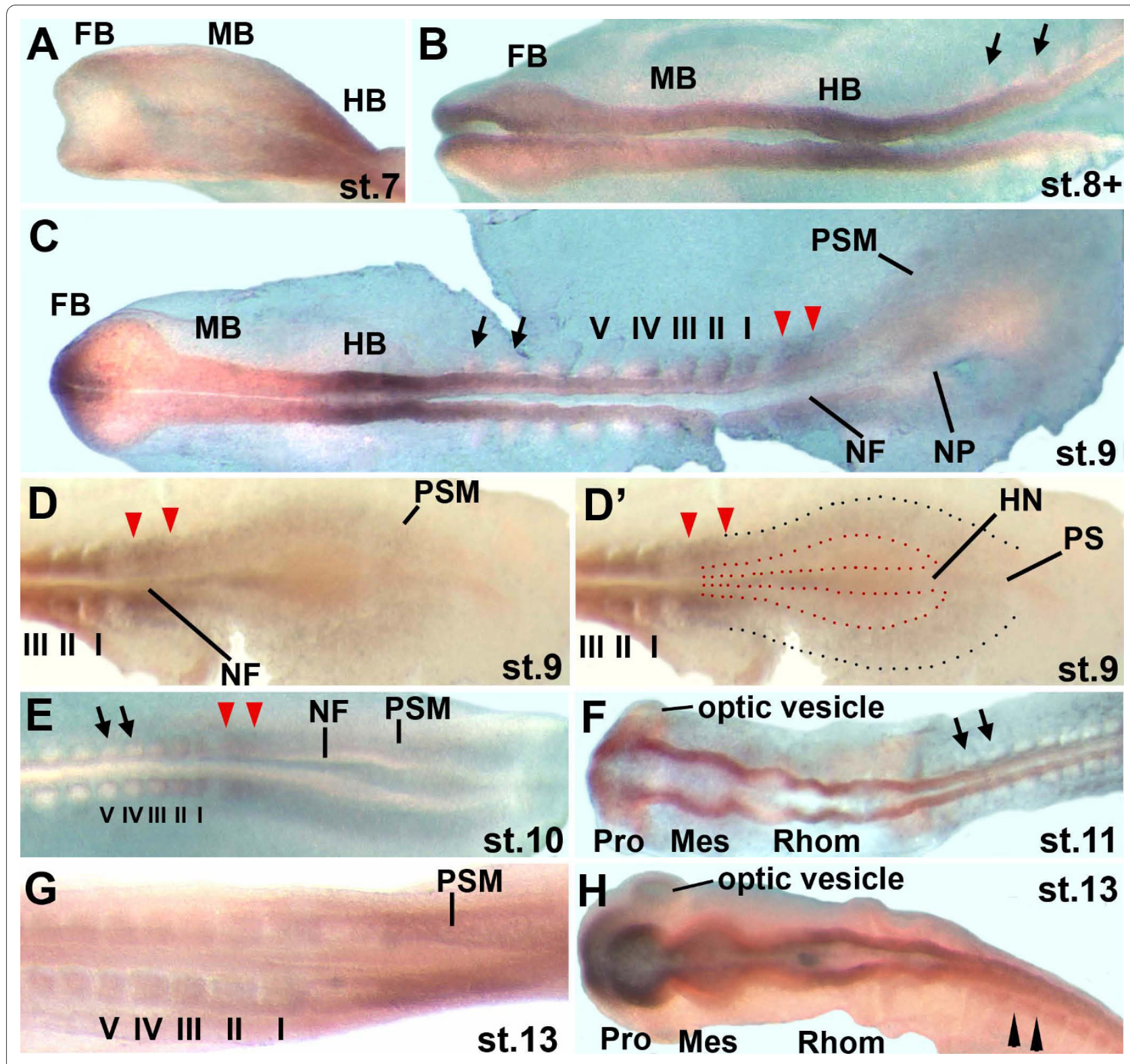

Figure 3 Expression of the zic 3 gene in chick embryos at HH stages 7 to 13 . A: zic 3 is expressed in the future forebrain in a limited and weak expression domain. It is broadly expressed in the future hindbrain. B: At stage 8+, weak zic3 expression continues in a limited region of the forebrain. It is expressed in the neural folds of the hindbrain and more weakly in the anterior trunk. C, D, D': In stage 9 embryos (7-9 somites), the first epithelial somites (somites I-III and sometimes somite IV) express zic3, while more anterior somites do not express zic3 (black arrows, C). zic 3 is expressed at low levels in the presomitic mesoderm and at a slightly increased level in the area that will form the next somite (red arrowheads). D and D': posterior region of a stage 9 embryo. In D', the area that represents the neural plate and expresses zic2 (see Figure 2B) is outlined with red dots. The outer limit of the adjacent presomitic mesoderm, which expresses zic3, is marked by black dots. E: At stage 10, low levels of zic3 expression continue in presomitic mesoderm and in epithelial somites I-III. The neural folds do not express zic3. F: zic3 is first expressed along the entire brain in stage 11 embryos. Anterior somites do not express zic3 (black arrows). G, H: By stage 13, anterior somites (H, black arrowheads) and the optic vesicles first express low levels of zic3. The presomitic mesoderm expresses zic3, while there is very little or no expression of zic3 in epithelial somites (G). The brain and anterior neural tube express zic3 (H), while the posterior neural tube does not (G). Abbreviations as in legend for Figure 1; NP: neural plate; black arrows: somites not expressing zic3; black arrowheads flank somite showing weak zic3 expression; red arrowheads: increased zic3 expression in presomitic mesoderm.

neural tube was unique, since it was expressed at low levels very early during formation of the neural plate (stage 6+; Figure 2A) and continued to be expressed along the entire trunk neural tube, trunk neural folds and neural plate throughout further early development (Figure 2B-I). Both $z i c 2$ and $z i c 3$ were expressed in continuous domains from the hindbrain to the trunk neural tube (Figures $2 \mathrm{C}$, D, G and 3C, F), while zic1 expression in the trunk and 


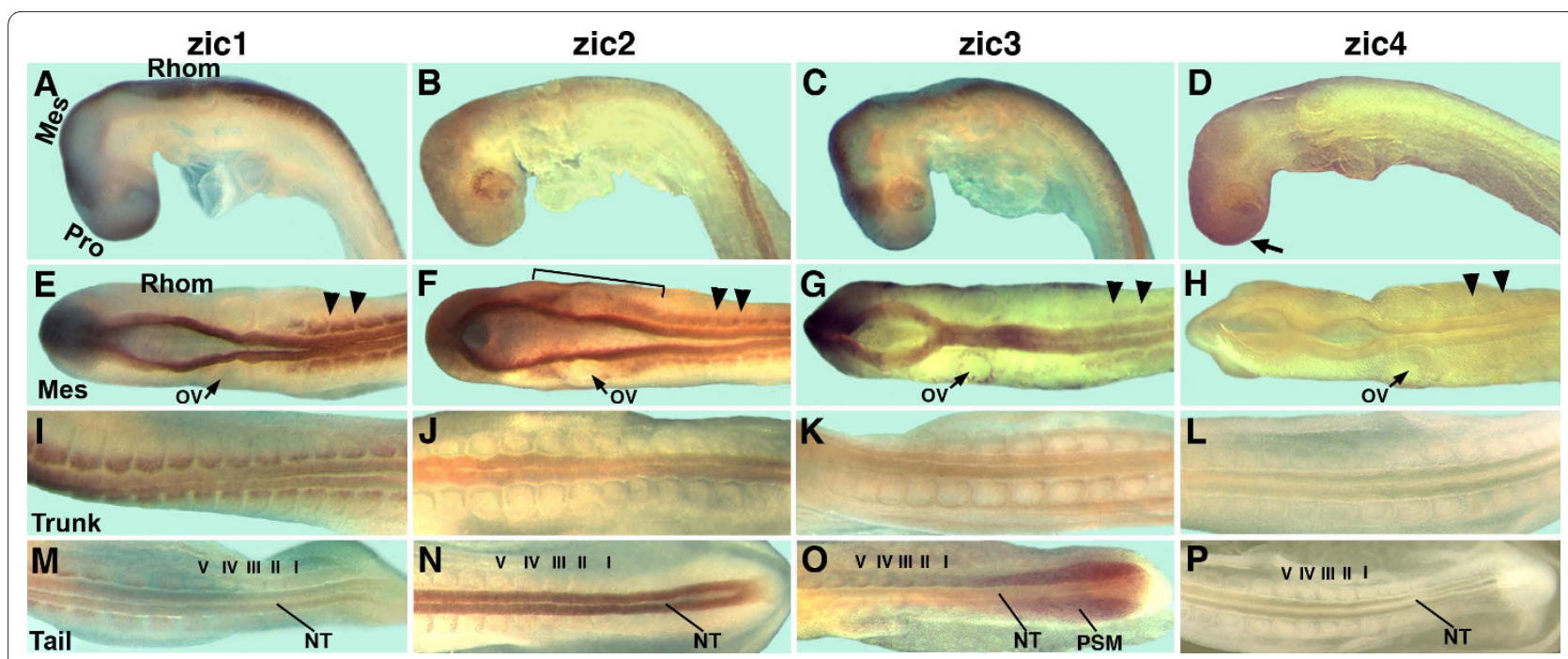

Figure 4 Comparison of zic1-4 gene expression in chick embryos at stage HH 14/15. A-D: side views of whole embryos; E-H: dorsal views of midbrain, hindbrain, anterior trunk; I-L: mid-trunk; M-P: tail with epithelial somites marked (I - V). A, E, I, M: zicl is expressed in the dorsal brain and in the neural tube, except in the most posterior neural tube (M). zicl is expressed in most somites. B, F, J, N: zic2 is expressed along the entire dorsal brain and neural tube of the trunk with enhanced expression in the neural tube of the tail (N). zic 2 is expressed in the developing eye (B), in the periotic mesoderm (F) and in anterior somites (F). C, G, K, O: zic3 is expressed in the dorsal brain, in the eye (C), and in the neural tube, except in the neural tube of the tail (O). zic3 is expressed in the presomitic mesoderm (O). D, H, L, P: zic4 is expressed in the anterior brain (D) and is not detectable in any other parts of stage 14/15 embryos. Pro: prosencephalon; Mes: mesencephalon; Rhom: rhombencephalon; ov: otic vesicle; NT: neural tube; PSM: presomitic mesoderm; arrowheads outline somites; arrow points to zic4 expression; bracket: periotic mesoderm. The stage of the embryos is $\mathrm{HH} 14$ with the exception of D, H: HH 14-; M, F, N, P: HH 15

hindbrain was discontinuous (Figure 1E). As in younger embryos, zic1 and zic3 expression in the trunk neural tubes of stage 14/15 and stage 18/19 embryos, tapered caudally (in stage18/19 embryos, diminished expression was limited to the tail tips), while zic2 expression remained strong to the most posterior extent of the neural folds/neural tube (Figures 4N, R; 5O, S). zic4 expression was undetectable in the trunks of embryos at any stage (Figures 4L, P; 5P, T).

Cross-sections of stage 14/15 embryos allowed more precise location of zic gene expression following in situ hybridization. The zic1-3 genes were expressed in the dorsal neural tubes of the mid-trunk and anterior trunk (Figure 6D, E, J, K, P, Q) and in the dorsal hindbrain (Figure $6 \mathrm{~F}, \mathrm{~L}, \mathrm{R})$, whereas zic4 was neither expressed in the trunk nor hindbrain (Figure $6 \mathrm{~S}-\mathrm{X}$ ). In the tail tip region, $z i c 2$ was expressed not only in the dorsal portion, but also throughout the remainder of the neural tube (Figure 6G).

In mice, decreased zic 2 expression causes both holoprosencephaly and spina bifida, a posterior neural tube closure defect $[16,20]$. Thus, expression of chicken $z i c 2$ in the neural plate and neural folds (Figure 2B, H) may be required for neural tube closure. This appears to be true for Zic proteins in Xenopus and zebrafish, since zebrafish $z i c 2 a$ and $z i c 5$ are necessary for hinge point formation during neurulation [38]. Further, we found that Zic factors directly induce an aquaporin gene $(a q p-3 b)$ in Xeno- pus that is specifically expressed in the neural folds and may contribute to neural tube closure [37].

\section{Somites}

During chick somite development, the presomitic mesoderm segments into epithelial somites (somites I-V). As new somites form, older somites compartmentalize into an epithelial dermomyotome and mesenchymal sclerotome. zic gene expression in the somites proceeded in two phases. During the first phase only zic3 expression occurred in newly formed somites, while in the second phase zic1-3 were expressed in more mature somites. Phase 1: In stage 7-10 embryos, zic3 was expressed at low levels in presomitic mesoderm, which included a stripe of slightly increased zic3 expression, where the next somite pair would form (red arrowheads, Figure 3C, D, D', E). In addition, zic3 was expressed in two or three of the most recently formed somites (Figure 3C-E). By stage 12, zic3 expression was largely limited to somite I and was uniformly expressed in presomitic mesoderm (not shown). The expression of zic3 in the presomitic mesoderm (Figure $3 \mathrm{C}, \mathrm{D}$ ) surrounded the expression domain of zic2 in the neural plate (Figure 2B). The relationship between these expression patterns is shown in Figure 3D', where red dots outline the zic2 expression domain (neural plate; see Figure 2B) and black dots indicate the outer limit of zic3 expression (mesoderm). Phase 2: The zic1-3 genes were expressed in the most anterior, mature somites. The onset of very low, but detectable expression in anterior 


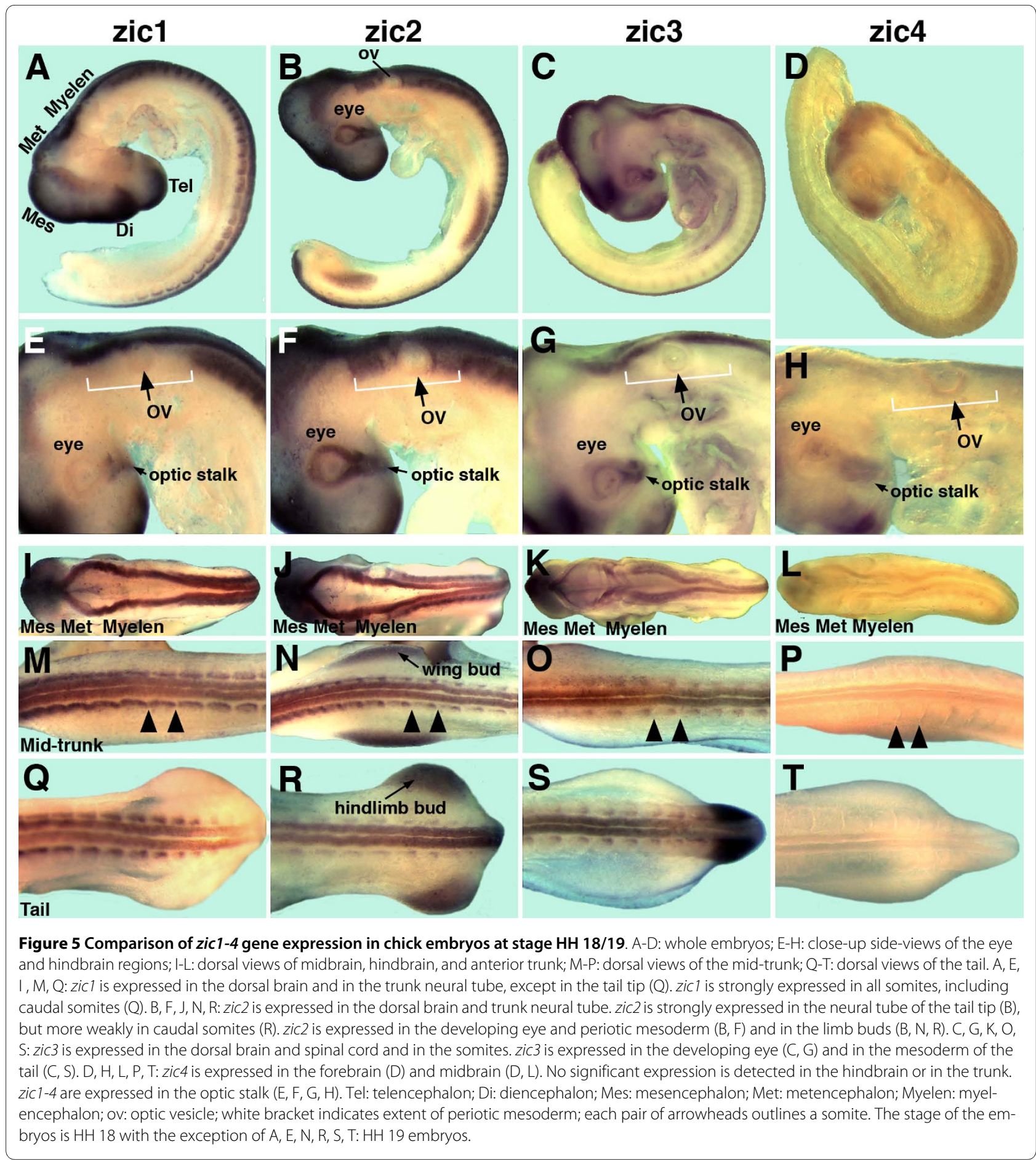

somites was stage 10 for zic1 (Figure 1D), stage 11 for $z i c 2$ (Figure 2G), and stage 12/13 for zic3 (Figure 3H). In stage $14 / 15$ embryos, zic1 expression extended to the most posterior somites (Figure 4I, M), including the dorsomedial region of recently formed somites (Figure 6C) [26]. zic2 and zic3 expression, however, was absent from more posterior somites (Figures 4J, K, N, O; 6I, J, O). In stage $14 / 15$ embryos, zic3 continued to be expressed in pre- somitic mesoderm (Figures 4O; 6M, N). Cryosections of mature somites in the anterior trunk showed that zic1 and $z i c 2$ were expressed in both the dermomyotome and in the sclerotome (Figure 6D, E, K) [26], while zic3 was expressed in the sclerotome with some expression in the dermomyotome of the anterior trunk (Figure 6P, Q). In stage 18/19 embryos, zic1-3 were expressed in somites along most of the anterior/posterior axis (Figure 5M-O, 

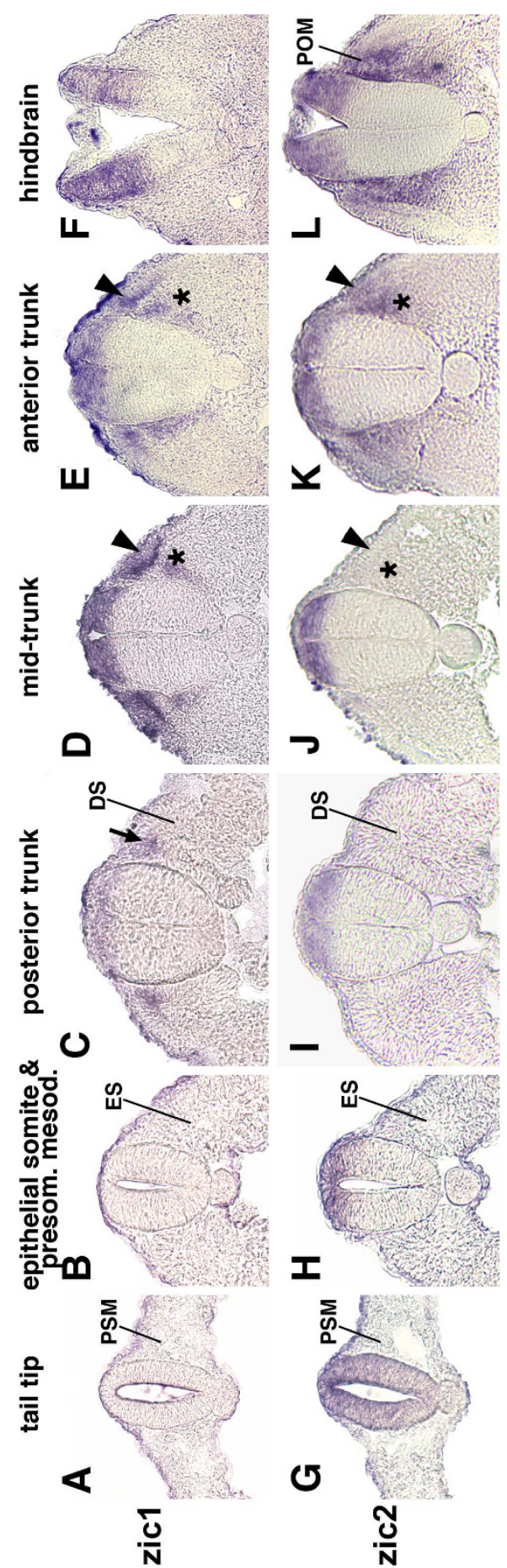

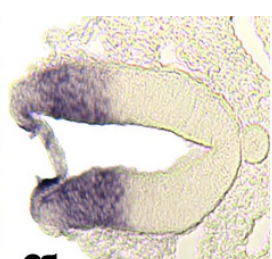

$\boldsymbol{\alpha}$
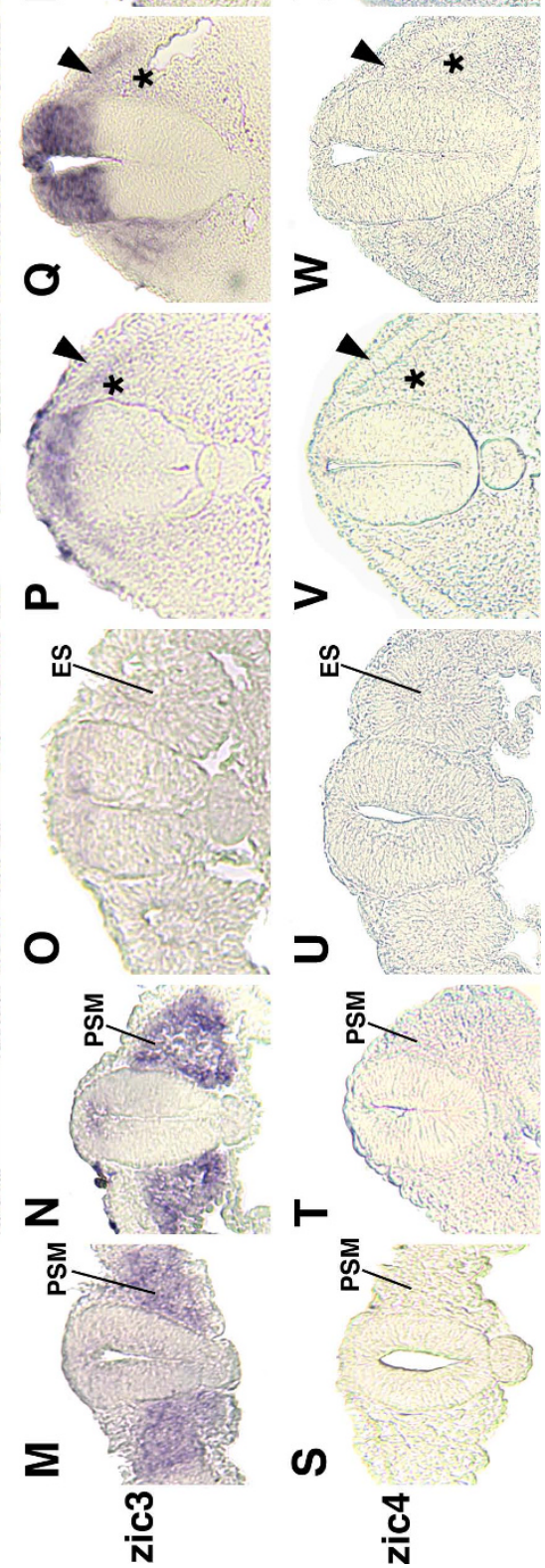

Figure 6 Sections of trunk and hindbrain regions of stage HH 14/15 embryos. A-F: zicl expression by in situ hybridization. zicl is not expressed in the posterior neural tube $(A, B)$. More rostrally, it is expressed in the dorsal neural tube and in the dorsal portion of recently formed somites (arrow) (C). zicl expression continues in the dorsal neural tube, dermomyotome (arrow heads), and sclerotome (asterisks) (D, E) and in the dorsal hindbrain (F). G-L: zic2 expression. zic2 is expressed throughout the dorsal/ventral axis of the neural tube in the tail (G). Rostral to the tail region, zic2 expression is restricted to the dorsal portion of the trunk neural tube $(\mathrm{H}-\mathrm{K})$. zic2 is expressed in the dermomyotome and sclerotome of rostral somites (K; arrow head and asterisk, respectively). It is expressed in the dorsal hindbrain and in the periotic mesoderm (L). M-R: zic3 expression. zic 3 is expressed in the presomitic mesoderm $(\mathrm{M}, \mathrm{N})$. It is not expressed in epithelial somites $(\mathrm{O})$ and only further rostrally in more mature somites in the sclerotome $(\mathrm{P}, \mathrm{Q}$; asterisks) and in the dermomyotome ( $Q$; arrow head). zic3 is expressed in the dorsal neural tube of the mid- and anterior trunk (P, Q) and in the dorsal hindbrain (R). S-X: zic4 is not expressed in the trunk or hindbrain of stage 14/15 embryos. PSM: presomitic mesoderm; ES: epithelial somite; DS: dissociating somite; POM: periotic mesoderm; arrowheads: dermomyotome; asterisks: sclerotome. 
Q-S). Since zic4 was not expressed in the trunk, no expression was detected in somites (Figures 4L, P; 5D, P, T; 6U-W). Migrating neural crest cells do not express zic1 [26] and serial sections suggest that zic2 and most likely $z i c 3$ are not expressed in migrating neural crest cells (not shown).

In mice, skeletal abnormalities occur when Zic1, Zic2, or Zic3 expression is compromised. This is presumably due to loss of $Z i c$ expression in the sclerotome [20,39,40], a region where expression of the zic1-3 genes was found in chick embryos (Figure 6D, E, K, P, Q). The ability of Zic proteins to stimulate cell proliferation $[10,11,25]$ may be important for the high rate of proliferation in the dorsomedial lip (DML) of the dermomyotome, where zic1 and $z i c 2$ were expressed in chick embryos (Figure 6D, E, K). In mice, Zic2 and Zic3 are required for proper somite formation, particularly with respect to early establishment of somitic integrity [11]. It is likely that zic3 in chick plays a comparable role due to its similar expression in presomitic mesoderm and epithelial somites. However, the significance of the stripes of zic gene expression in the presomitic mesoderm is not known and further analysis will be needed to understand their role in somite formation.

\section{Periotic mesoderm}

Among the $z i c 1-4$ genes, $z i c 2$ was uniquely expressed in the periotic mesoderm. This expression became visible at stage 12 (Figure 2I) and continued in stage 14/15 (whole mount embryo Figure 4F; section Figure 6L) and stage 18/19 embryos (Figure 5F).

\section{Limb buds}

zic2 was expressed in stage $18 / 19$ wing and hindlimb buds (Figure 5B, N, R), while zic1, 3, and 4 transcripts were not detected in limb buds. In a previous study [26], we detected zic1 expression in the limb buds of stage 21 embryos. Further studies suggested that $z i c 1$ expression in limb buds was transient during stages 20/21-24 (unpublished). This is consistent with a lack of zic1 expression in the limb buds of stage 26 embryos [28].

\section{Expression levels of zic genes}

The zic1-3 genes were expressed at very low levels in chick embryos at early developmental stages (stages 7-11 in particular). Thus, minimal expression levels may be sufficient to mediate Zic function during early neural tube and somite formation. zic1-3 expression levels increased significantly with progressing maturity of the cranial region during stages 13-15. Increased zic1-3 expression is also seen in the trunk region, although this is not apparent until stages 18-19. This delay may be due to the anterior to posterior gradient of maturity in chick embryos, where cranial regions develop ahead of trunk regions. Higher expression levels of zic1-3 during stages 13-15 anteriorly and stage 18-19 in the trunk may be required to help direct cellular decisions relating to proliferation versus differentiation in the maturing cranial and trunk neural tube, and in the maturing somites $[25,26,41]$. Increased Zic protein levels may impact binding to regulatory sites in $\mathrm{Zic}$ target genes and may also affect the stoichiometry with interacting proteins [42-44]. This, in turn, may modulate Zic protein function as a transcriptional activator or repressor and influence the affinities of Zic proteins for specific target sites, leading to context-dependent regulation of target gene sets. That transcript levels are dynamic and can vary at different developmental stages is also illustrated by expression of the $t b x 1$ transcription factor gene that is transcribed at very low levels in the cranial region in stage 10 embryos and shows greatly increased expression at stage 12 [45]. Before the significance of the differing zic gene expression levels can be truly understood, additional work is needed to identify the relevant transcriptional targets, to correlate zic mRNA levels with Zic protein levels, to identify Zic functional partners and potential post-translational modifications, to determine the effect of these factors on Zic protein activity, and to determine their effects on the expression of known target genes.

\section{Comparison of zic gene expression in different species}

The current study in chick embryos indicates that the zic1-3 genes are expressed during dorsal axial development, both in the neural tube and in somites, while expression of zic4 appears limited to the dorsal brain. In mouse and Xenopus embryos, zic4 is expressed in the brain and in the trunk and its expression pattern is generally thought to resemble that of zic1 at a weaker expression level $[34,46,47]$. Thus, it was suggested that the adjacent zic1 and zic4 genes are subject to a certain degree of coordinate regulation. Indeed, in zebrafish, the adjacent zic2a and zic5 genes possess common regulatory elements [10]. In chick embryos, the expression patterns of the zic1 and zic4 genes appeared to be quite different, suggesting that coordinate regulation is unlikely for the zic1 and zic4 genes in birds.

In general, the expression patterns of zic genes in the neural tube and somites are relatively similar across species. The similarities of zic1, zic2, and zic3 gene expression in chick to that in other organisms suggests conserved functions for these genes. However, there are also variations in zic gene expression across species. These are particularly evident in the presomitic mesoderm and eyes. Zic2 and Zic3 are expressed in mouse presomitic mesoderm [11], while only zic3 was expressed in chick presomitic mesoderm (this study). Further, Zic1-3 are expressed in mouse eyes [47], zic1 and zic2 in Xenopus eyes [34], and zic2 and zic3 in chick eyes (this study). While these differences may be species-specific, other differences in zic gene expression are less consistent. For 
example, Warner et al. (2003) report zic1-3 expression in chick periotic mesoderm, while our findings and a study in mouse showed only zic2 expression in periotic mesoderm [46]. Besides species-specific variations, additional explanations for observed differences in zic gene expression between species and within the same species may be based on more technical considerations. These may include the possibility of different degrees of probe specificity for individual zic genes that were used in previous studies (the probes used in this study were specifically designed to preclude cross-hybridization). Another possible explanation for differences in zic gene expression patterns includes the possibility of inaccuracies in the precise staging of embryos within the same species and inaccuracies inherent in comparing equivalent stages across species, which could be very important for transient expression features of particular zic genes. Further, it is possible that zic genes are alternately spliced, which might cause probes to reveal different expression domains. However, to date, alternate splice forms have not been reported for zic genes. Finally, since zic genes may be able to compensate for each other, it is possible that the roles of zic genes may be distributed slightly differently among zic genes in different species, resulting in different expression patterns.

\section{Conclusions}

We have followed the expression of the zic1-4 genes during early chick development, resulting in a comprehensive side-by-side study of zic1-4 gene expression throughout neurulation and somitogenesis. We find that the zic1-3 genes are expressed in partially overlapping domains in the dorsal neural tube and in dorsal portions of somites. In addition, the $z i c 2$ gene is uniquely expressed along the entire early neural plate and zic3 is uniquely expressed in the surrounding presomitic mesoderm, suggesting that Zic2 and Zic3 specifically regulate developmental genes during initial formation of the neural tube and somites, respectively. Further, zic2 is expressed in the periotic mesoderm and in limb buds and both zic 2 and zic 3 are expressed in developing eyes, suggesting involvement of these genes in regulating the formation of these tissues. We also show that the zic4 gene is expressed in dorsal regions of the future head, but does not appear to be expressed in the chick hindbrain or trunk. Overall, zic gene expression in chick and other organisms shows significant similarities, indicating that the particular strengths of the chick developmental system will complement current studies of zic genes in other organisms. At the same time, the species-specific differences in zic gene expression that we observe may point to important evolutionary differences, which are of interest in their own right.

\section{Methods}

Generation of Gene-Specific Antisense RNA in situ Hybridization Probes

Design of a gene-specific antisense RNA probe for the chicken zic1 gene was based on its published sequence [25]. For the chicken $z i c 2$, zic3, and zic4 genes, homology to these genes in mouse, human, and Xenopus was used to identify exon regions for zic2, zic3, and zic4 in the chicken genome. The identification of homologous regions for chicken zic2 and zic3 was additionally aided by unpublished partial sequence for these genes, kindly provided by Dr. Sara Ahlgren (Children's Memorial Research Center, Chicago). As expected, we found high homology among the four chicken zic genes in the zinc finger region and in the regions flanking the zinc fingers. Comparing the identified sequences, we carefully selected regions that were sufficiently divergent to result in antisense RNA probes that would not cross-react. At the same time, the chosen regions had to be long enough to produce useful probes. Not all regions chosen gave rise to working probes and multiple regions were tested to obtain functional gene-specific probes. For zic1 and zic2, PCR products were synthesized from stage 18 chick cDNA, which was obtained by reverse transcription of isolated total RNA. These PCR products were TA cloned into pGEM-T (Promega) and transcribed from the resulting plasmids to generate antisense RNA probes. For zic3 and zic4, T7 promoter-containing PCR products were synthesized from stage 18 chick cDNA. The gel-purified PCR products were used as templates for synthesis of antisense RNA probes using T7 polymerase. The primers used to clone pieces of zic1 and zic2 and for synthesis of PCR products for $z i c 3$ and $z i c 4$ were:

zic1 forward: 5'-GCGCTAAAACAAAACAGCGA-3'; zic1 reverse: 5'-CTGTATTTACAAGAGGGAGTGGG-3' (497 bp in 3'UTR)

zic2 forward: 5'-CССТССТСТCССТССТССТ-3'; zic2 reverse: 5'-ACGCTGATTTCCTCACAACC-3' (441 bp in 3'UTR)

zic3 forward: 5'-CAGCAAGGACTCCACGAAAAC-3'; zic3 reverse: 5'-CTAATACGACTCACTATAGGCGACCCCATCAGATGAGAAT-3' (ca. 730 bp; little 3' coding region and mostly 3 'UTR).

zic4 forward: 5'-GCTCCAGTTCAAAGCCACAT-3'; zic4 reverse: 5'-CTAATACGACTCACTATAGGGAGCCAGGTTCACGTTCAG-3' (ca. 600 bp; 5'UTR and 5' coding region).

The bold bases represent T7 RNA polymerase promoter sequence.

Extensive comparison of the probe sequences that were amplified by these primer sets among each other, comparison of each of these sequences to the regions of all zic genes in the chicken genome and to the complete sequences of the zic2-4 genes in mouse, human and 
Xenopus (since we do not have complete sequence information for these three genes in chicken) allowed us to conclude that any cross-reactivity of these probes with other zic genes was extremely unlikely. A lack of crossreactivity of our probes was further suggested by the gene expression patterns generated by each probe. The expression patterns produced by each of the four probes showed unique features such that none of the staining patterns could be a subset of the staining pattern generated by another one of the probes.

Finally, our exhaustive sequence comparisons of each of the four chicken zic genes with all zic genes of mouse, human and Xenopus allowed us a very high degree of certainty that we had correctly identified each chicken zic gene. Further, our extensive independent comparisons were in agreement with the annotations provided in the Ensembl chicken genome database.

\section{In situ Hybridization}

White Leghorn chicken embryos were staged according to [30]. Whole mount in situ hybridization was performed as in [48] with the modifications described in [26]. NBT/BCIP substrate (Sigma) was used for color detection. The embryos were not post-treated with alcohol, since such treatment proved to remove too much of the fainter stain, which was critical for assessing zic gene expression domains. Hence the red-brown color of the NBT/BCIP reaction product in our images. A pink shadow was digitally softened in Figure $2 \mathrm{~F}$ and the orange color in Figure 3H was diminished slightly. Both manipulations did not alter the data content of either panel.

\section{Cryosections}

Embryos were sectioned following in situ hybridization. Stained embryos were cryoprotected in graded sucrose solutions and embedded in OCT compound. Cryosections of $14 \mu \mathrm{m}$ thickness were collected on Superfrost Plus (VWR) slides. The sections were rehydrated in $1 \times$ PBS and mounted in 1:1 glycerol/PBS.

\section{Competing interests}

The authors declare that they have no competing interests.

\section{Authors' contributions}

AM performed, analyzed and photographed the in situ hybridizations at stages 14/15 and 18/19, cryosectioned and photographed stage 14/15 embryos, and helped edit the manuscript. CM performed in situ hybridization and photography of earlier stage embryos, supervised the project, and wrote the manuscript. Both authors read and approved the final manuscript.

\footnotetext{
Acknowledgements

We thank Kristin Junette, Sara Hildreth, and Dr. Anne Rusoff for help during various stages of this project to generate the countless embryos and sections that were required to obtain representative images. We also thank Dr. Sara Ahlgren for the unpublished partial sequences of the chicken zic2 and zic3 genes. We are grateful to Dr. E. Jean Cornish for critical reading of the manuscript. This work was supported by NSF grants IOB-0417242 and IOS-0846168 to C.S.M. and by undergraduate research support to A.R.M. from the Montana State University Undergraduate Scholars Program and from the Complex Biological Sys-
}

tems Summer Undergraduate Research Program, which is funded by the Howard Hughes Medical Institute.

\section{Author Details}

Department of Cell Biology and Neuroscience, Montana State University, Bozeman, MT 59717, USA

Received: 10 November 2009 Accepted: 16 June 2010

Published: 16 June 2010

\section{References}

1. Merzdorf CS: Emerging roles for zic genes in early development. Dev Dyn 2007, 236:922-940.

2. Brewster R, Lee J, Ruiz i Altaba A: Gli/Zic factors pattern the neural plate by defining domains of cell differentiation. Nature 1998, 393:579-83.

3. Elsen GE, Choi LY, Millen KJ, Grinblat Y, Prince VE: Zic1 and Zic4 regulate zebrafish roof plate specification and hindbrain ventricle morphogenesis. Dev Biol 2008, 314:376-92.

4. Kuo JS, Patel M, Gamse J, Merzdorf C, Liu X, Apekin V, Sive H: Opl: a zinc finger protein that regulates neural determination and patterning in Xenopus. Development 1998, 125:2867-82.

5. Merzdorf CS, Sive HL: The zic1 gene is an activator of Wnt signaling. Int J Dev Biol 2006, 50:611-7.

6. Mizuseki K, Kishi M, Matsui M, Nakanishi S, Sasai Y: Xenopus Zic-related-1 and Sox-2, two factors induced by chordin, have distinct activities in the initiation of neural induction. Development 1998, 125:579-87.

7. Nakata K, Koyabu Y, Aruga J, Mikoshiba K: A novel member of the Xenopus Zic family, Zic5, mediates neural crest development. Mech Dev 2000, 99:83-91.

8. Nakata K, Nagai T, Aruga J, Mikoshiba K: Xenopus Zic3, a primary regulator both in neural and neural crest development. Proc Natl Acad SciUSA 1997, 94:11980-5.

9. Nakata K, Nagai T, Aruga J, Mikoshiba K: Xenopus Zic family and its role in neural and neural crest development. Mech Dev 1998, 75:43-51.

10. Nyholm MK, Wu SF, Dorsky Rl, Grinblat Y: The zebrafish zic2a-zic5 gene pair acts downstream of canonical Wnt signaling to control cell proliferation in the developing tectum. Development 2007, 134:735-46.

11. Inoue T, Ota M, Ogawa M, Mikoshiba K, Aruga J: Zic1 and Zic3 regulate medial forebrain development through expansion of neuronal progenitors. J Neurosci 2007, 27:5461-73.

12. Furushima K, Murata T, Kiyonari H, Aizawa S: Characterization of Opr deficiency in mouse brain: subtle defects in dorsomedial telencephalon and medioventral forebrain. Dev Dyn 2005, 232:1056-61.

13. Grinberg I, Northrup H, Ardinger H, Prasad C, Dobyns WB, Millen KJ: Heterozygous deletion of the linked genes $\mathrm{ZIC} 1$ and $\mathrm{ZIC} 4$ is involved in Dandy-Walker malformation. Nat Genet 2004, 36:1053-5.

14. Grinberg I, Millen KJ: The ZIC gene family in development and disease. Clin Genet 2005, 67:290-6.

15. Carrel T, Purandare SM, Harrison W, Elder F, Fox T, Casey B, Herman GE: The $X$-linked mouse mutation Bent tail is associated with a deletion of the Zic3 locus. Hum Mol Genet 2000, 9:1937-42.

16. Elms $P$, Siggers $P$, Napper $D$, Greenfield A, Arkell R: Zic2 is required for neural crest formation and hindbrain patterning during mouse development. Dev Biol 2003, 264:391-406

17. Gebbia M, Ferrero GB, Pilia G, Bassi MT, Aylsworth A, Penman-Splitt M, Bird LM, Bamforth JS, Burn J, Schlessinger D, et al: X-linked situs abnormalities result from mutations in ZIC3. Nat Genet 1997, 17:305-8.

18. Herman GE, El-Hodiri HM: The role of ZIC3 in vertebrate development. Cytogenet Genome Res 2002, 99:229-35.

19. Klootwijk R, Schijvenaars MM, Mariman EC, Franke B: Further characterization of the genetic defect of the Bent tail mouse, a mouse model for human neural tube defects. Birth Defects Res A Clin Mol Teratol 2004, 70:880-4.

20. Nagai T, Aruga J, Minowa O, Sugimoto T, Ohno Y, Noda T, Mikoshiba K: Zic2 regulates the kinetics of neurulation. Proc Natl Acad Sci USA 2000, 97:1618-23

21. Ware SM, Peng J, Zhu L, Fernbach S, Colicos S, Casey B, Towbin J, Belmont $\mathrm{JW}$ : Identification and functional analysis of ZIC 3 mutations in heterotaxy and related congenital heart defects. Am J Hum Genet 2004, 74:93-105.

22. Maurus D, Harris WA: Zic-associated holoprosencephaly: zebrafish Zic1 controls midline formation and forebrain patterning by regulating 
Nodal, Hedgehog, and retinoic acid signaling. Genes Dev 2009, 23:1461-73.

23. Warr N, Powles-Glover N, Chappell A, Robson J, Norris D, Arkell RM: Zic2associated holoprosencephaly is caused by a transient defect in the organizer region during gastrulation. Hum Mol Genet 2008, 17:2986-96.

24. Aruga J, Minowa O, Yaginuma H, Kuno J, Nagai T, Noda T, Mikoshiba K Mouse Zic1 is involved in cerebellar development. J Neurosci 1998, 18:284-93.

25. Aruga J, Tohmonda T, Homma S, Mikoshiba K: Zic1 promotes the expansion of dorsal neural progenitors in spinal cord by inhibiting neuronal differentiation. Dev Biol 2002, 244:329-41.

26. Sun Rhodes LS, Merzdorf CS: The zic1 gene is expressed in chick somites but not in migratory neural crest. Gene Expr Patterns 2006, 6:539-545.

27. Warner SJ, Hutson MR, Oh SH, Gerlach-Bank LM, Lomax MI, Barald KF: Expression of ZIC genes in the development of the chick inner ear and nervous system. Dev Dyn 2003, 226:702-12.

28. Lin JC, Cepko CL: Granule cell raphes and parasagittal domains of Purkinje cells: complementary patterns in the developing chick cerebellum. J Neurosci 1998, 18:9342-53

29. Zhang J, Jin Z, Bao ZZ: Disruption of gradient expression of Zic3 resulted in abnormal intra-retinal axon projection. Development 2004, 131:1553-62.

30. Hamburger $\mathrm{V}$, Hamilton $\mathrm{HL}$ : A series of normal stages in the development of the chick embryo. J Morphol 1951, 88:49-92.

31. Van Straaten HW, Janssen HC, Peeters MC, Copp AJ, Hekking JW: Neural tube closure in the chick embryo is multiphasic. Dev Dyn 1996, 207:309-18.

32. Brown SA, Warburton D, Brown LY, Yu CY, Roeder ER, Stengel-Rutkowski S, Hennekam RC, Muenke M: Holoprosencephaly due to mutations in ZIC2, a homologue of Drosophila odd-paired. Nat Genet 1998, 20:180-3.

33. Sanek NA, Grinblat Y: A novel role for zebrafish zic2a during forebrain development. Dev Biol 2008, 317:325-35.

34. Fujimi TJ, Mikoshiba K, Aruga J: Xenopus Zic4: Conservation and diversification of expression profiles and protein function among the Xenopus Zic family. Dev Dyn 2006.

35. Li S, Shin Y, Cho KW, Merzdorf CS: The Xfeb gene is directly upregulated by Zic1 during early neural development. Dev Dyn 2006, 235:2817-27.

36. Keynes R, Krumlauf R: Hox genes and regionalization of the nervous system. Annu Rev Neurosci 1994, 17:109-32.

37. Cornish EJ, Hassan SM, Martin JD, Li S, Merzdorf CS: A microarray screen for direct targets of Zic1 identifies an aquaporin gene, aqp-3b, expressed in the neural folds. Dev Dyn 2009, 238:1179-94.

38. Nyholm MK, Abdelilah-Seyfried S, Grinblat Y: A novel genetic mechanism regulates dorsolateral hinge-point formation during zebrafish cranial neurulation. J Cell Sci 2009, 122:2137-48.

39. Aruga J, Mizugishi K, Koseki H, Imai K, Balling R, Noda T, Mikoshiba K: Zic1 regulates the patterning of vertebral arches in cooperation with Gli3. Mech Dev 1999, 89:141-50.

40. Purandare SM, Ware SM, Kwan KM, Gebbia M, Bassi MT, Deng JM, Vogel H, Behringer RR, Belmont JW, Casey B: A complex syndrome of left-right axis, central nervous system and axial skeleton defects in Zic3 mutant mice. Development 2002, 129:2293-302.

41. Ebert PJ, Timmer JR, Nakada Y, Helms AW, Parab PB, Liu Y, Hunsaker TL, Johnson JE: Zic1 represses Math1 expression via interactions with the Math1 enhancer and modulation of Math1 autoregulation. Development 2003, 130:1949-59.

42. Bagutti C, Forro G, Ferralli J, Rubin B, Chiquet-Ehrismann R: The intracellular domain of teneurin-2 has a nuclear function and represses zic-1-mediated transcription. J Cell Sci 2003, 116:2957-66.

43. Koyabu Y, Nakata K, Mizugishi K, Aruga J, Mikoshiba K: Physical and functional interactions between Zic and Gli proteins. J Biol Chem 2001, 276:6889-92.

44. Mizugishi K, Hatayama M, Tohmonda T, Ogawa M, Inoue T, Mikoshiba K, Aruga J: Myogenic repressor I-mfa interferes with the function of Zic family proteins. Biochem Biophys Res Commun 2004, 320:233-40.

45. Dastjerdi A, Robson L, Walker R, Hadley J, Zhang Z, Rodriguez-Niedenfuhr M, Ataliotis P, Baldini A, Scambler P, Francis-West P: Tbx1 regulation of myogenic differentiation in the limb and cranial mesoderm. Dev Dyn 2007, 236:353-63

46. Gaston-Massuet C, Henderson DJ, Greene ND, Copp AJ: Zic4, a zincfinger transcription factor, is expressed in the developing mouse nervous system. Dev Dyn 2005.
47. Nagai T, Aruga J, Takada S, Gunther T, Sporle R, Schughart K, Mikoshiba K: The expression of the mouse Zic1, Zic2, and Zic3 gene suggests an essential role for Zic genes in body pattern formation. Dev Biol 1997, 182:299-313.

48. Nieto MA, Patel K, Wilkinson DG: In situ hybridization analysis of chick embryos in whole mount and tissue sections. Methods Cell Biol 1996, 51:219-35.

doi: 10.1186/1756-0500-3-167

Cite this article as: McMahon and Merzdorf, Expression of the zic1, zic2, zic3, and zic4 genes in early chick embryos BMC Research Notes 2010, 3:167

\section{Submit your next manuscript to BioMed Central and take full advantage of:}

- Convenient online submission

- Thorough peer review

- No space constraints or color figure charges

- Immediate publication on acceptance

- Inclusion in PubMed, CAS, Scopus and Google Scholar

- Research which is freely available for redistribution 